\title{
Design and Implementation of Photo Voltaic System: Arduino Approach
}

\author{
Neeraj Vijay Kale \\ Department of Electronics Engineering, \\ Walchand Institute of Technology, Solapur \\ Maharashtra, India, 413006.
}

\author{
Prashant Shivasharan Malge \\ Department of Electronics Engineering, \\ Walchand Institute of Technology, Solapur \\ Maharashtra, India, 413006.
}

\begin{abstract}
Photovoltaic (PV) is a renewable energy source and has become an important source of power for a wide range of applications. Design and implementation of an Arduino based Photovoltaic system are presented in this paper. Proposed system includes Maximum power point tracking (MPPT) technique, sun tracking technique to generate maximum power from PV panel and monitoring software for monitoring the performance of Photovoltaic system. The paper describes the design of MPPT unit, sun tracking unit and development of monitoring software for PC. Finally experimental results validate the performance of the proposed system.
\end{abstract}

\section{Keywords}

Maximum Power Point unit, Sun tracking unit, Monitoring Software.

\section{INTRODUCTION}

The basic need for development and existence of human life is an energy. Fossil fuels (Coal, oil and natural gas), hydroelectric power and nuclear power are the commercial sources of energy. [2] Total world consumption of energy is increasing at an alarming rate year after year. According to Key World Energy Statistics 2012 published by the International Energy Agency (IEA), total world final consumption of energy has increased from 4672Mtoe (million ton of oil equivalent) in 1973, to 8677 Mtoe in 2010 . On the contrary, the fossil fuels are rapidly depleting and reserves of the fossil fuels are gradually coming to an end. Because of the increased world total consumption of energy and depletion of resources the cost of the commercial resources has achieved high hike. [2]. Because of these problems, the focus is now shifting towards renewable energy sources. Solar energy is a renewable energy source that can lead us away from our commercial energy sources. Solar energy is clean, renewable and sustainable unlike fossil fuels such as coal, oil and natural gas and is also sustainable.

Photo voltaic systems have two major problems; the conversion efficiency of electric power generation is very low about $10-24 \%[3]$, and get reduced under low irradiation conditions.

PV panels have a nonlinear voltage-current characteristic [4], with a distinct maximum power point (MPP), which depends on the environmental factors, such as temperature and irradiation [3]. In order to continuously harvest maximum power from the solar panels, they have to operate at their MPP despite the inevitable changes in the environment. MPPT strongly tracks this operating point to generate maximum power from PV panel.

Since the Earth rotates, and orbits around the sun, the relative position of the sun changes and is a major factor in the performance of PV systems [13]. To generate the maximum power from solar panel, solar panel must be aligned perfectly towards the sun; hence MPPT is used in conjunction with a mechanical sun tracking in the proposed system. To understand the performance of PV system monitoring software is developed.

For proposed system Arduino is used. Arduino is an open source electronic prototype platform that consist of 8-bit Atmel AVR microcontroller such as Atmega328. More information about Arduino is available at http//Arduino. cc.

The outline of the paper is as follows. The design of maximum power point tracking and sun tracking is described in section 2 and 3 respectively. Section 4 describes monitoring software. Experimental results are presented in section 5 . Finally section 6 concludes the paper.

\section{DESING OF MAXIMUM POWER POINT TRACKING}

This section describes maximum power point tracking technique and its implementation in the proposed system.

\subsection{Maximum Power Point Tracking (MPPT)}

The PV cell V-I characteristic is nonlinear and varies with irradiation [4]. Maximum Power point i.e. $P_{M A X}$ of PV modules is defined as the point on IV curve where we get maximum current and voltage [7] as shown below in Fig.1 at $V_{M P}$ and $I_{M P}$ maximum power of PV panel is located, $V_{M P}$ and $I_{M P}$ are the maximum voltage and current respectively. Maximum power point tracking is the control technique that maintains the PV modules operating point at its Maximum Power Point. MPPT technique operates the PV module in a manner that allows the module to produce all the power it is capable of. The terminal voltage of PV panel is adjusted so that the maximum power can be extracted. MPPT technique involves the design of DC to DC buck converter. MPPT algorithm is embedded in Arduino which adjust the duty cycle of DC to DC converter according MPPT algorithm by comparing the voltage and current of PV module [5]. Different methods of MPPT are available such as Perturb-andobserve (P\&O) method, Incremental conductance (INC) method, and Constant voltage method [7]. For this system Perturbation and observation algorithm is used. 


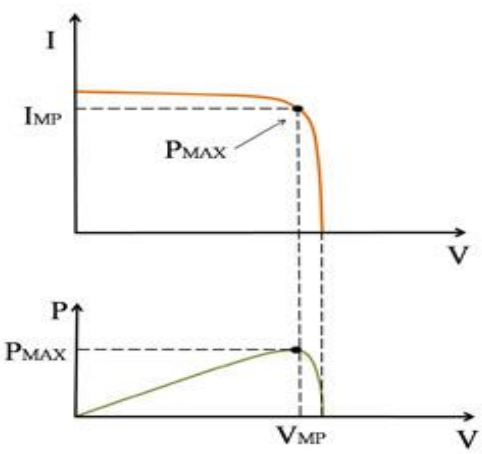

Fig 1: Maximum Power for an I-V Sweep.

\subsection{MPPT Unit:}

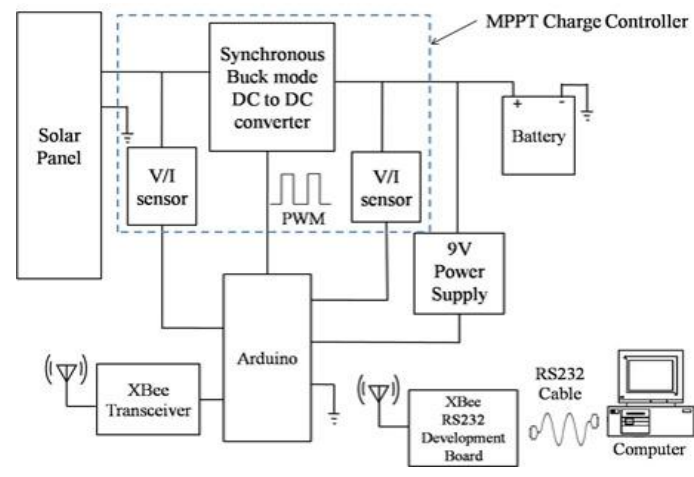

Fig 2: Block diagram of MPPT unit.

Fig 2 shows a block diagram of MPPT unit. It consists of a solar panel, synchronous buck mode DC to DC Converter, voltage and current sensing elements, an Arduino board, 12V Lead acid battery, Xbee Transceiver, power supply.

For proposed system Arduino Duenilanov board has been used. The board consists of Atmel Atmega328 microcontroller. V/I sensor senses the output voltage and current of PV panel .These analog signals are given to the analog channels on Arduino board. The MPPT algorithm is embedded in Atmega328 microcontroller. The panel output is fed to a synchronous buck mode DC-DC converter that steps down the panel voltage to a usable voltage appropriate for battery charging. The switching pulse (PWM) necessary to operate the DC-DC converter is generated by Atmega328 microcontroller. The duty cycle of the PWM to the DC to DC converter that separates the panel and the battery is varied by a small according to the MPPT algorithm. Sensed solar voltage, current and battery voltage are sent to the PC through the wireless Xbee module. Monitoring software provides Solar I-V plot, Battery I-V plot and PV power plot based on these data.

Charge controller consists of DC to DC synchronous Buck Converter, voltage and current sensors, four LED to show the current charge status as shown in Fig 3. Pin D8, D9 connect to the digital pin of D8, D9 of Arduino respectively. These pins are used to provide PWM to IR2104 MOSFET driver IC. Similarly pins D4, D5, D6, D7 are connected to digital pin D4, D5, D6, D7 of Arduino respectively. These pins are used to indicate the current charge status i.e. ON state, buck state, float state or $\mathrm{OFF}$ state. Pin A0, A1, A2 are connected to analog pin A0, A1, A2 of Arduino. A0 used as PV voltage sensor input, A1 used as current sensor input and A2 used as battery voltage sensor input to Arduino.

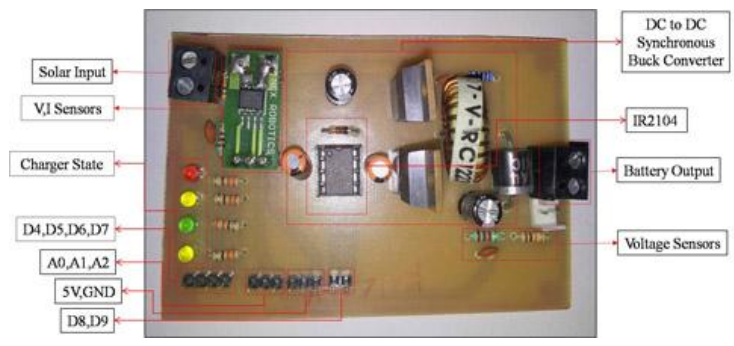

Fig 3: Photograph of Charge Controller.

3. DESIGN OF SUN TRACKING:

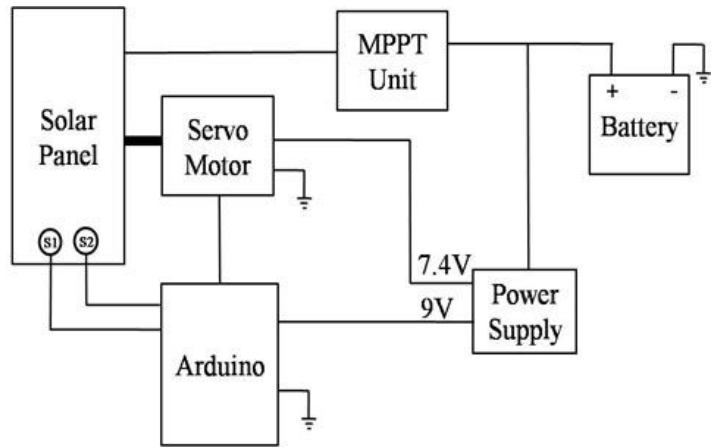

Fig 4: Block Diagram of sun tracking unit.

Fig 4 shows a block diagram of the sun tracking unit. It consists of a servo motor, two LDR sensors S1 and S2, battery and power supply unit. Two sensors which track light levels from the East/West are used to move a servo motor and rotates the panel East/West for tracking the strongest light level. The output of these sensors is connected to analog the channels of Adruino. Based on the voltage input PWM signal is generated by Arduino and is used to drive the servo motor.MPPT unit will charge the battery as explained previously. The power supply unit is designed to generate a supply voltage of $7.4 \mathrm{~V}$ for servo motor and $9 \mathrm{~V}$ for Arduino board. The servo motor is attached to PV panel by mechanical assembly.

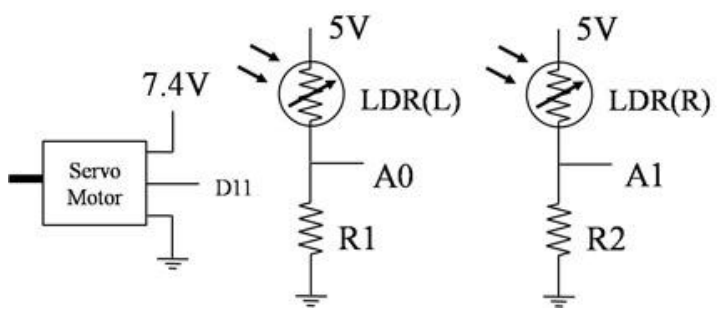

Fig 5: Circuit diagram of sensor and servo motor connection.

Fig 3 shows the circuit diagram of sensor and servo motor connection. The two light sensors are basically Light Dependent Resistors (LDR). As shown in Fig 6 these are mounted at $90^{\circ}$ to each other, the left sensor points $45^{\circ}$ to the left, and the right sensor points $45^{\circ}$ to the right. These sensors are also shielded, so they will see the brightest light levels when pointing directly at the light source. If the light source moves, a shadow will cast onto the sensor, changing its resistance. When the resistance changes output of these sensors also gets changed. The difference between the outputs of both the sensors is calculated as an error. Error zero means they are at the same light level, an error negative means the light is brighter to the right, and positive means the light is brighter to the left. The servo is then sent up with a position 
value, and simply incremented or decremented the position values based on error to rotate the PV panel east and west to find the optimum balance light levels on the sensors again.
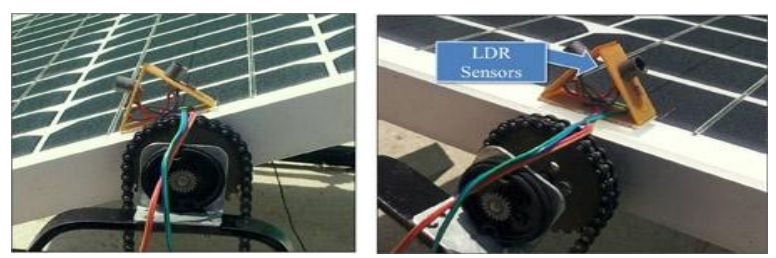

Fig 6: Photograph showing how LDR sensors are placed on PV panel

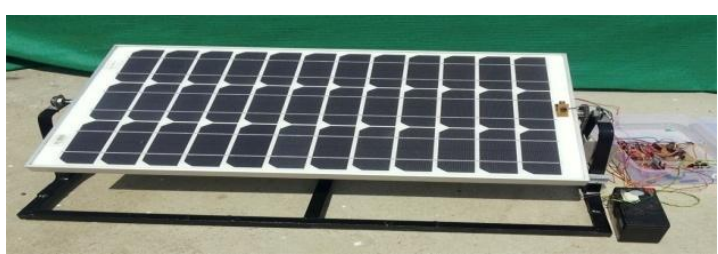

a)

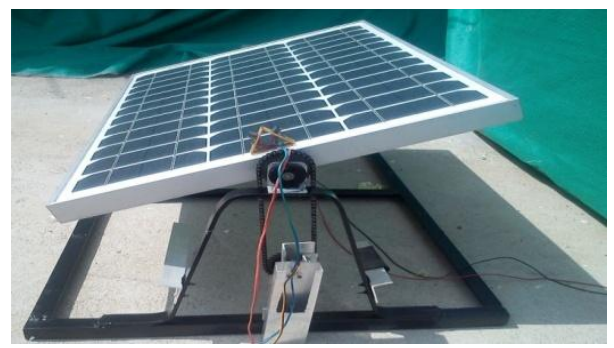

b)

Fig 7: a) Front view and b) Side view of System.

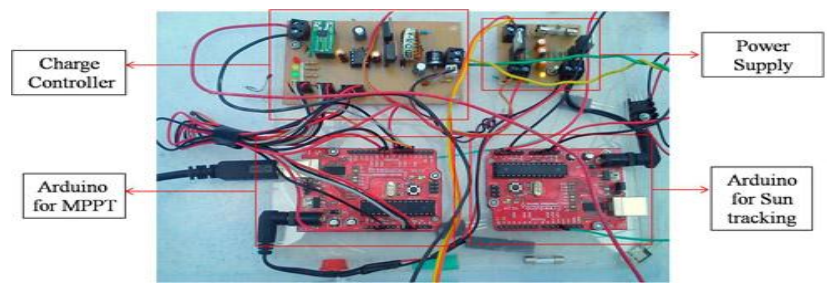

Fig 8: Circuit boards.

\section{MONITORING SOFTWARE}

Fig 9 shows the snapshot of monitoring software. The software provides four charts, $1^{\text {st }}$ chart provides solar I-V plot, $2^{\text {nd }}$ chart provides battery I-V plot, and $3^{\text {rd }}$ chart provides power plot. The fourth chart shows the current charge status, the PWM duty cycle, date and time.

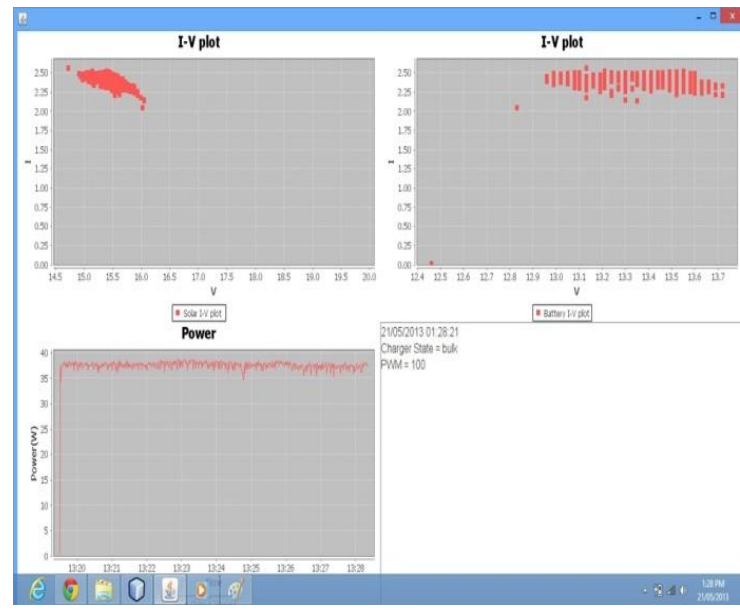

Fig 9: Snapshot of monitoring system

\section{RESULTS}

Following are the results taken for MPPT technique and sun tracking technique.

\subsection{MPPT}

To study the effect of Maximum power point tracking technique $12 \mathrm{~V}, 50 \mathrm{~W}$ PV panel is used. The monitoring software provides solar I-V plot, battery I-V plot, and power plot. To study the effect of the MPPT charge controller, MPPT charge controller power output is compared with PWM based charge controller power output. Fig.10 (a) \& (b) and Fig.11 (a) \& (b) shows power plot for MPPT based charge controller and PWM based charge controller respectively for two different weather condition i.e. clear sky condition and cloudy condition respectively. In similar way power plot for four different days are saved. Table I shows a comparison of average power generated between PWM based and MPPT based charge controllers for four different days with two weather conditions. 


\subsubsection{Readings taken on 21/05/2013 under clear sky condition}

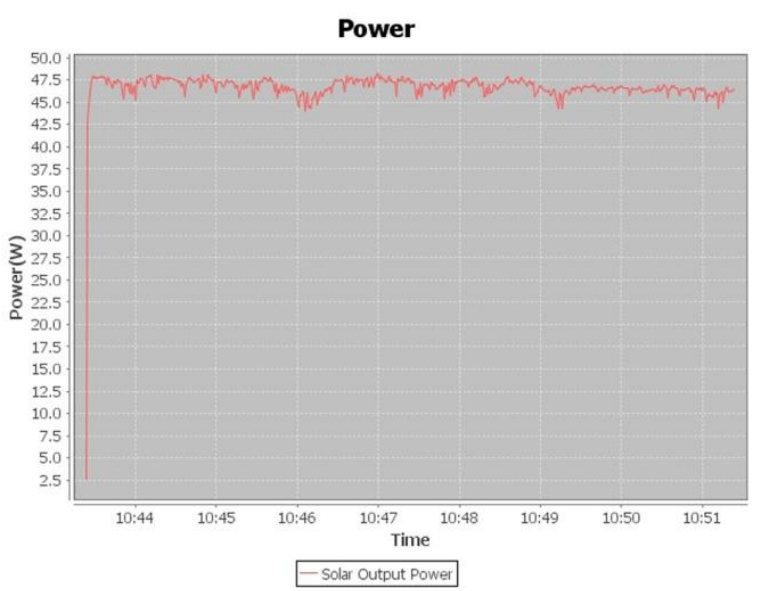

a)

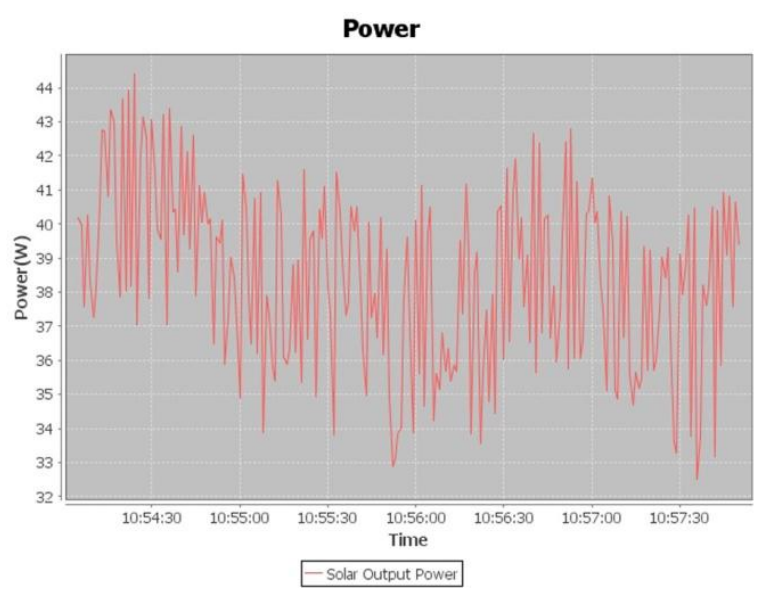

b)

Fig 10: a) MPPT Based charge controller b) PWM Based charge controller

\subsubsection{Readings taken on 13-06-2013 under cloudy condition:}

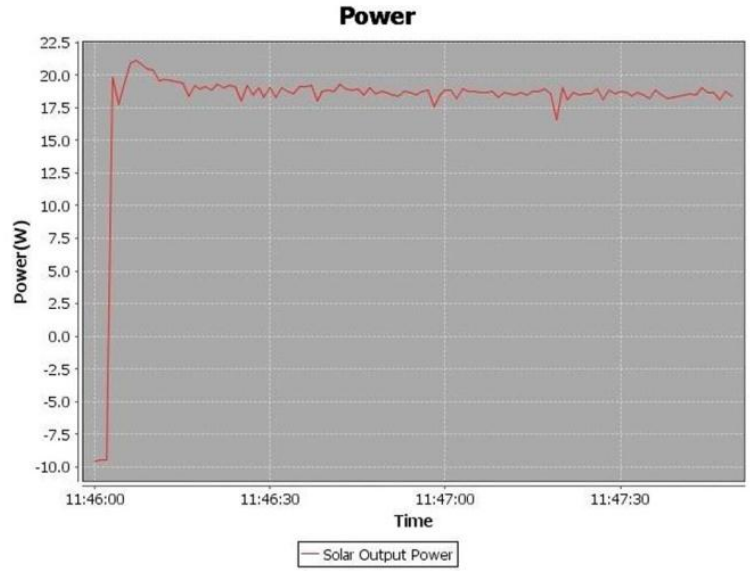

a)

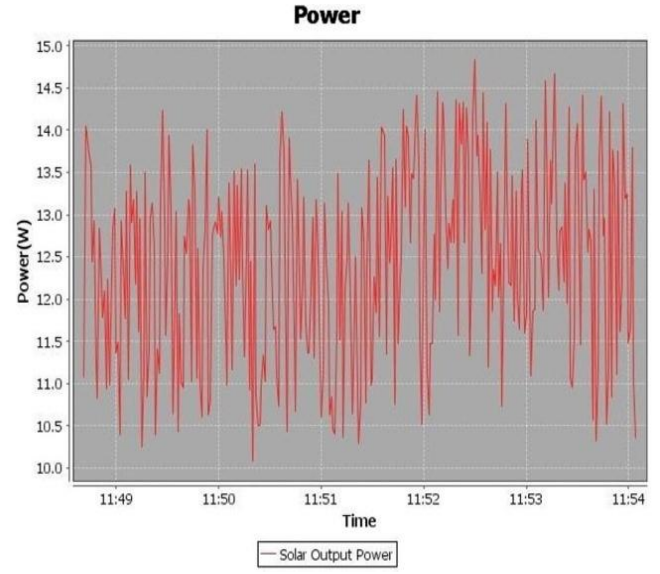

b)

Fig 11: a) MPPT Based charge controller b) PWM Based charge controller.

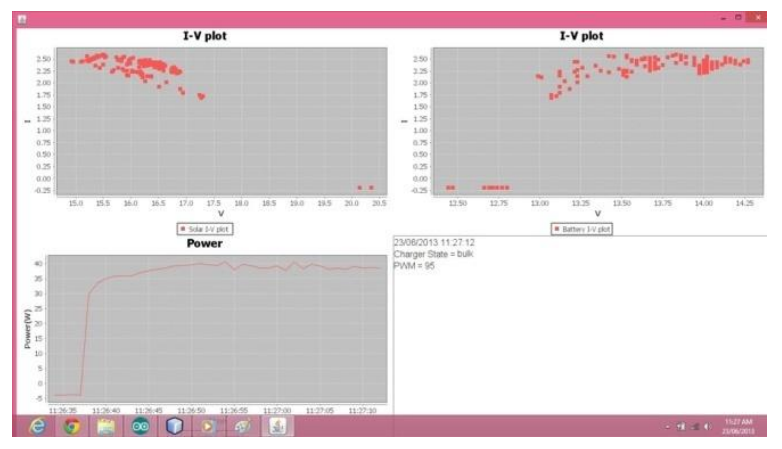

a)

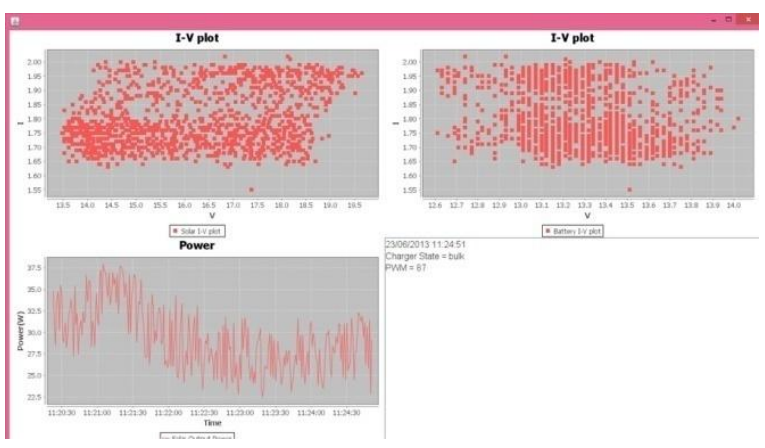

b)

Fig 12: Snapshot of monitoring software taken for a) MPPT Based charge controller b) PWM Based charge controller. 
Table 1: Average Power Generated

\begin{tabular}{|c|c|c|c|c|}
\hline Date & $\begin{array}{c}\text { Weather } \\
\text { Condition }\end{array}$ & $\begin{array}{c}\text { PWM } \\
\text { based }\end{array}$ & $\begin{array}{c}\text { MPPT } \\
\text { based }\end{array}$ & $\begin{array}{c}\text { Power } \\
\text { Comparison }\end{array}$ \\
\hline $11 / 05 / 2013$ & Clear sky & $31.15 \mathrm{~W}$ & $39.8 \mathrm{~W}$ & $16 \%$ \\
\hline $21 / 05 / 2013$ & Clear sky & $40.77 \mathrm{~W}$ & $47 \mathrm{~W}$ & $12.28 \%$ \\
\hline $13 / 06 / 2013$ & Cloudy & $13.84 \mathrm{~W}$ & $17.9 \mathrm{~W}$ & $8.14 \%$ \\
\hline
\end{tabular}

From Table 1, on 11/05/2013 and 21/05/2013 under clear sky condition MPPT based charge controller generating respectively $16 \%$ and $12.28 \%$ more power as compared to PWM based charge controller. On 13/06/2013 and 23/06/2013 under cloudy condition MPPT based charge controller generating $8.14 \%$ and $14 \%$ more power as compared PWM based charge controller.

Fig 12 shows a) shows a snapshot of monitoring software taken for (a) MPPT based charge controller and (b) PWM based charge controller. From Fig (a) Battery IV plot, battery is charged with the almost constant current of $2.5 \mathrm{~A}$. Whereas in case of PWM based charge controller, the battery is charged with the current varying from 1.65 to $2 \mathrm{~A}$. (See Fig (b).)

Fig 13 is snapshot of monitoring system showing how battery charging is managed. When the battery is fully charged, its voltage becomes $14.5 \mathrm{~V}$. The charger goes to float state. Under float state PWM duty cycle become $87 \%$ and the power coming from the panel to the battery is dropped down to $15 \mathrm{~W}$ to maintain its float charging state. With this the overcharging of the battery is avoided.

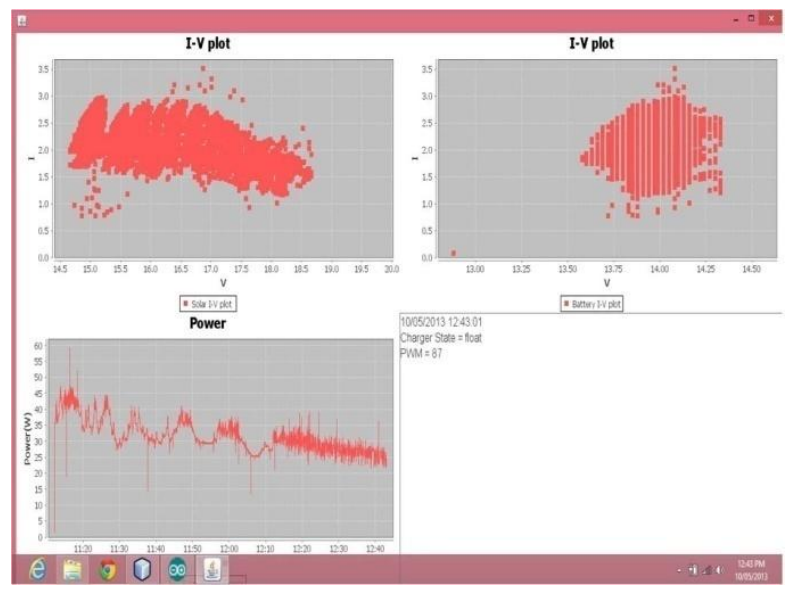

Fig 13: Snapshot of monitoring system showing float charge state.

\subsection{Sun tracking:}

To understand the effect of sun tracking, solar power is plotted with four different positions of PV panel with respect to sun position. Fig 14 shows four different positions of PV panel with respect to the sun. Fig 15 shows plots of power for ${ }^{5.2 .1}$ four different positions of PV panel. In case of position D PV panel is perfectly aligned towards the sun. In case of position A, plane of PV panel is at $90^{\circ}$ With normal toward the sun, in case of position $\mathrm{B}$ it is at $75^{\circ}$ with normal toward sun, and in case of position $\mathrm{C}$ it at $45^{\circ}$ with normal but in the opposite direction of the sun.
From Fig. 15 in the case of position $\mathrm{C}$ power generated from PV panel is very less because PV panel is in the opposite direction of the sun. Whereas in case of position $\mathrm{D}$ power generated from PV panel is maximized because the PV panel is perfectly aligned towards the sun. In case of position B and position $\mathrm{D}$ there is very little difference in angle, but in the case of the position B PV panel is not perfectly aligned towards the sun; hence power generated from a PV panel for position $\mathrm{B}$ is less than that for position $\mathrm{D}$. That is in order to generate maximum power from PV panel; panel must have to be aligned with the sun. Even a small angle variation causes a larger drop down in power.

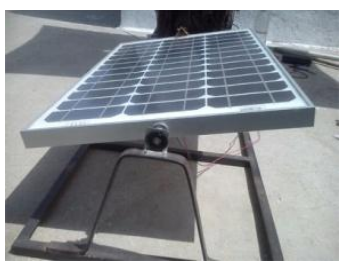

Position A

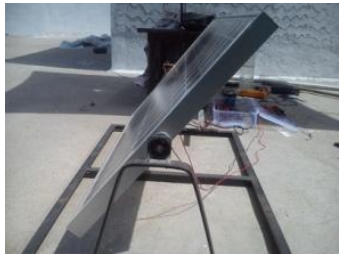

Position C

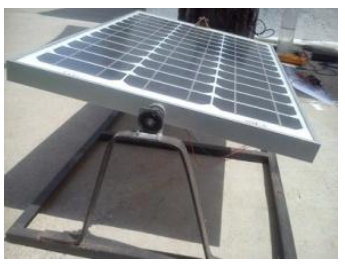

Position B

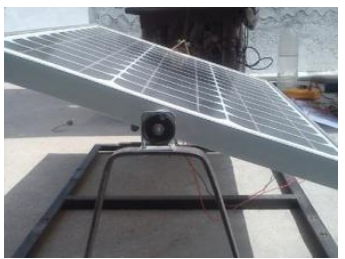

Position D
Fig 14: Four different position of PV panel with Respect to sun position.

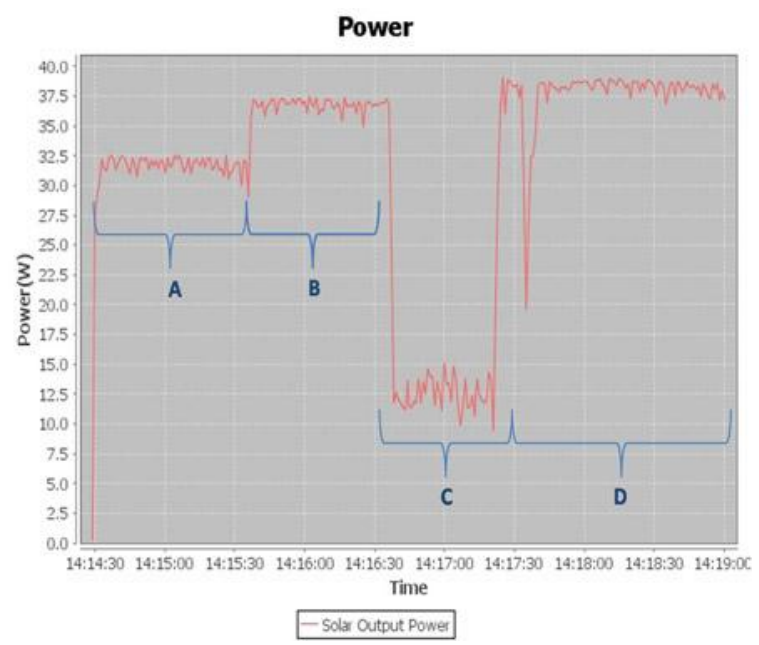

Fig 15: Plot of output power for four different positions of PV panel.

Optimum Angle of PV Panels by Month for Solapur City:

Table 2 shows the optimum angle for PV panel in degrees from vertical by month. Optimum angle PV panel varies throughout the year, depending on the seasons and location. These solar angles are calculated by using solar-anglecalculator available at http://solarelectricityhandbook.com 
Table 2. Optimum angles of PV panel by Month

\begin{tabular}{|l|l|l|l|l|l|}
\hline Jan & Feb & Mar & Apr & May & Jun \\
\hline $56^{\circ}$ & $64^{\circ}$ & $72^{\circ}$ & $80^{\circ}$ & $88^{\circ}$ & $96^{\circ}$ \\
\hline Jul & Aug & Sep & Oct & Nov & Dec \\
\hline $88^{\circ}$ & $80^{\circ}$ & $72^{\circ}$ & $64^{\circ}$ & $56^{\circ}$ & $48^{\circ}$ \\
\hline
\end{tabular}

Table 3 shows output generated for different angles of PV panel with respect to vertical. Since readings are taken on 28/06/2013, from Table I optimum angle of PV panel for the month June is $96^{\circ}$. From Table II Maximum power is generated when PV panel is at an angle in between $80^{\circ}$ to $96^{\circ}$ with respect to vertical.

Table 3. Reading taken on $28 / 06 / 2013$ at $1: 30 \mathrm{pm}$

\begin{tabular}{|l|r|r|r|}
\hline \multicolumn{1}{|c|}{ Angle } & Current & Voltage & Power \\
\hline $0^{\circ}$ & $0.99 \mathrm{~A}$ & $18 \mathrm{~V}$ & $17.82 \mathrm{~W}$ \\
\hline $16^{\circ}$ & $1.09 \mathrm{~A}$ & $18 \mathrm{~V}$ & $19.62 \mathrm{~W}$ \\
\hline $32^{\circ}$ & $1.98 \mathrm{~A}$ & $18 \mathrm{~V}$ & $35.64 \mathrm{~W}$ \\
\hline $48^{\circ}$ & $2.16 \mathrm{~A}$ & $18 \mathrm{~V}$ & $38.88 \mathrm{~W}$ \\
\hline $64^{\circ}$ & $2.25 \mathrm{~A}$ & $18 \mathrm{~V}$ & $40.5 \mathrm{~W}$ \\
\hline $80^{\circ}$ & $2.26 \mathrm{~A}$ & $18 \mathrm{~V}$ & $40.68 \mathrm{~W}$ \\
\hline $96^{\circ}$ & $2.26 \mathrm{~A}$ & $18 \mathrm{~V}$ & $40.68 \mathrm{~W}$ \\
\hline $112^{\circ}$ & $2.24 \mathrm{~A}$ & $18 \mathrm{~V}$ & $40.32 \mathrm{~W}$ \\
\hline $128^{\circ}$ & $2.14 \mathrm{~A}$ & $18 \mathrm{~V}$ & $38.52 \mathrm{~W}$ \\
\hline $144^{\circ}$ & $2.04 \mathrm{~A}$ & $18 \mathrm{~V}$ & $36.72 \mathrm{~W}$ \\
\hline $160^{\circ}$ & $1.94 \mathrm{~A}$ & $18 \mathrm{~V}$ & $34.92 \mathrm{~W}$ \\
\hline
\end{tabular}

\section{CONCLUSION:}

This paper describes the design and implementation of MPPT techniques in conjunction with mechanical sun tracking technique and development of monitoring software for PC. Experimental results conclude that MPPT based charge controller generates average $12 \%$ more power as compared to
PWM based charge controller. MPPT based charge controller increases battery health by charging the battery at constant charging current and avoiding overcharging. Maximum power is generated when PV panels are perfectly aligned towards sun i.e. In order to generate maximum power from a PV panel, the panel must have to be aligned with the sun. Even a small angle variation causes a larger drop down in power. Thus MPPT in conjunction with mechanical sun tracking generates more power as compared PV system that contains fixed panel and PWM based charge controller.

\section{REFERENCES}

[1] Handbook on Energy Conscious Buildings by J.K. Nayak J.A. Prajapati- May 2006.

[2] Fossil Fuels and Pollution: The Future of Air Quality(book)- Julie Kerr Casper

[3] Solar Electricity Handbook - 2013 Edition.

[4] Solar Cells and Their Applications by By Lewis M. Fraas, Larry D. Partain.

[5] Thin Film Solar Cells: Fabrication, Characterization and Applications by Jef Poortmans, Vladimir

[6] Evaluation of Micro Controller Based Maximum Power Point Tracking Methods Using dSPACE Platform by Yen-Jung Mark Tung, Dr. Aiguo Patrick ,Dr. NirmalKumar Nair.

[7] Fundamentals of Photovoltaic Modules and Their Applications-Gopal Nath Tiwari, Swapnil Dubey

[8] Techniques for Maximizing Efficiency of Solar Energy Harvesting Systems by Pai H. Chou and Sehwan Kim.

[9] Power Electronics Handbook By Muhammad Rashid.

[10] Electronic Devices and Circuit Theory By Nashelsky

[11] Issa Bataresh, "Power Electronic Circuits," John Wiley \& Sons, Inc., 2004

[12] Buck-Converter Design Demystified, B Donald Schelle \& Jorge Castorena.

[13] Solar Tracking Systems: Leonard L. Northrup Jr

[14] Servo motor control - embedded-lab.com

[15] Sensors and Transducers By Ian Sinclair 